\title{
Življenje besed v Bibliji: od nog do glave
}

\author{
Jožica Narat (Ljubljana)
}

IZVLEČEK: Članek je besedoslovna obravnava besed noga in glava $v$ Dalmatinovi Bibliji, kontrolno pa tudi v Japljevem in najnovejšem slovenskem svetopisemskem prevodu. S tem je nakazana razvojna črta, primerjava posameznih mest z Luthrom, Rosalinom in Vulgato pa pokaže odnos naših prevodov do svojih predlog.

ABSTRACT: This article is a lexicological study of the words noga (foot) and glava (head) in Jurij Dalmatin's Bible. It also examines the two words in Jurij Japelj's translation and the latest Slovenian translation of the Bible. This reveals a developmental line, and comparison of individual sections with Martin Luther's and Franz Rosalino's translations, as well as the Vulgate, demonstrates the relation of Slovenian translations to these models.

0 Članek je besedoslovna obravnava besed noga in glava, ki se - zaradi njune središčnosti $\mathrm{v}$ besednem sestavu je to predvidljivo - pojavljata tako v Dalmatinovem biblijskem prevodu iz leta $1584^{1}$ kot tudi v Japljevem, ki je začel izhajati leta 1784, tj. točno 200 let za Dalmatinovim (prva knjiga vsebuje evangelije), konec njegovega izdajanja pa sega v leto 1802 , ko je izšla zadnja, deseta knjiga. ${ }^{2}$ Stalnost

1 Dalmatin je začel prevajati Staro zavezo v prvi polovici sedemdesetih let. Njegov Jezus Sirah (JESVS SIRAH) je izšel leta 1575 kot prvi ljubljanski tisk, tri leta kasneje (1578) je bilo natisnjeno Peteroknjižje (BIBLIE, TV IE, VSIGA SVETIGA PISMA PERVI DEIL, VKATERIM SO TE PET MOSESSOVE BVQVE, sdai peruizh is drugih iesikou vta Slouenski sueiftu ftolmazhene), čez dve leti (1580) pa Pregovori (SALOMONOVE PRIPVVISTI). Celotna Biblija je izšla leta 1584 v Wittenbergu.

2 Tako imenovani Japljev biblijski prevod je delo več prevajalcev, ime pa je dobil po organizatorju del in prevajalcu v prvem prevajalskem obdobju - duhovniku Juriju Japlju, doma iz Kamnika, ki je v času prevajanja služboval na Ježici pri Ljubljani. Pri delu je sodelovalo večje število prevajalcev in pregledovalcev, ki so popisani v uvodih k posameznim knjigam. Peteroknjižje je izšlo leta 1791, prevedla pa sta ga Jurij Japelj in Blaž Kumerdej. V tem času je prišlo v prevajalski ekipi že do korenitih sprememb: Japelj je prevajal po črki, njegovi sodelavci pa so začeli prevajati po smislu. Glavni zagovornik in izvajalec prevajanja po smislu je bil Jožef Škrinjar, ki je med drugim prevedel tudi Vi- 
$4 \quad$ in spremenljivost obeh samostalnikov sta ugotavljani oz. analizirani na izbranem besedilnem korpusu - Prva in Druga Mojzesova knjiga ter Visoka pesem - in to na osnovi popolnih samostalniških izpisov v dvovrstičnem sobesedilu. ${ }^{3}$

$1 \mathrm{~V}$ Dalmatinovi Bibliji se beseda noga pojavlja 435-krat, od tega $\mathrm{v}$ konkordančno izpisanih in zaradi tega posebej obravnavanih delih $(1 \mathrm{Mz}, 2 \mathrm{Mz}$ in Vp) 77-krat, primerjava teh 77 mest z Japljem pa pokaže, da je bilo na teh mestih čez 200 let 10 zapisov nog manj, torej 67, in da se v 56 pojavitvah noge Dalmatin in Japelj prekrivata, $\mathrm{tj}$. v 73 \% Dalmatin in v 84 \% Japelj. Vzrokov za izpust noge v Japljevem prevodu je več: nadomestna uporaba zaimka, zgoščevanje besedila in zato opuščena ponovitev besede ali uporaba druge besede.

1.1 (1-2) Noga v Bibliji opomenja zlasti del telesa (človeka, živali, tudi nadnaravnega bitja), ki ga lahko razložimo (1a) 'okončina bitja ali nadnaravnega bitja, namenjena za oporo trupa, premikanje' (She je tukaj en Ionatanou Syn, hrom na nogah - 2 Sam 9,3; fo vidili Israelfkiga Boga. Pod njegovimi nogami je bilu, kakòr enu dellu is lepiga Saphiroviga kamina - $2 \mathrm{Mz} 24,10$ ); (1b) 'okončina živali kot jed' (pèr Ognju pezhenu, njegovo glavo, shnjegovimi nogami inu shnjegovim drobom - $2 \mathrm{Mz} 12,9$ ); (2) 'del te okončine od gležnjev do konca prstov' (palce na nyh defni nogi-2 Mz 29,20; Issuj tvoje zhreule is tvoih nug - Joz 5,15; Naj fe vam

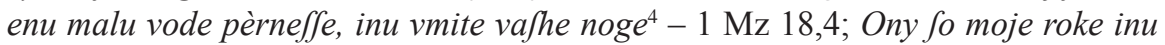
noge Jkus prebyli - Ps 22,17). Japelj ne prinaša na teh mestih nobenih sprememb, enkrat samkrat (1 Mz 49,10) pa je zamenjal Dalmatinovo nogo s pomensko ožjimi ledji: Krajleva paliza néma od Iuda vseta biti, ni mojster od njegovih nug ${ }^{5} \rightarrow \ldots$ tudi ne ta vajvoda od njegóvih lédi. ${ }^{6}$

Če vzamemo za izhodišče konkordance treh Japljevih bibličnih besedil, pa vidimo, da je z nogo Japelj nadomestil kar 3 Dalmatinove dele noge: bedra, ${ }^{7}$

soko pesem - izšla je leta 1798. O različnih predlogah za Japljev svetopisemski prevod - Japelj naj bi jih uporabljal kombinirano - piše natančno Breznik 1928.

3 Konkordančni program je pripravil mag. France Baraga.

4 Umivanje nog velja v deželi, kjer so poti prašne in popotniki hodijo bosi ali v sandalih, za osnovno dolžnost gostoljubnosti. Umivanje nog je bila zadeva sužnjev. (Grabner-Haider - Krašovec 1984: 739-740.) Je pa med Judi to veljalo za skrajno ponižujoče opravilo; celo če je Jud postal suženj, mu njegov judovski gospodar ni smel naložiti tega opravila (SP 1997, 1627). Zagonetnejši je primer je noge ${ }^{d} v^{\prime} m a f l i$ vmival, vendar ga razlaga ob robu ${ }^{d}$ Vmafli) tu je, ker fim vfiga obilnu inu sadofti imèl) dovolj jasno razloži: gre za frazem, ki pomeni uživanje izobilja. Noge so objekt tudi v zvezah z glagoli omakati, osnažiti, žalbati, močiti s solzami, kušati/kušovati, treti/otreti z lasmi, kopati v'tiga Nevernika krij.

5 Dalmatinov prevod se prekriva z Luthrom: Es wird das ${ }^{a}$ Scepter von Juda nicht entwendet werden / noch ein Meister von seinen füssen.

6 Z Japljem se prekriva Rosalinov prevod: noch der Fürst von seinen Lenden.

7 D: inu on je hramal na fvoji bedri $\rightarrow \mathrm{J}$ : on pak je na eni nogi fhantovu hodil (1 Mz 32,31). Luther ima na tem mestu ujemalno z Dalmatinom: Vnd er hincket an seiner Hüfft, Rosalino pa se prekriva z Japljem: er aber hinkte an einem Fuße. 
goleno, ${ }^{8}$ peta $^{9}$ - izbor je bil tako pri Dalmatinu kot pri Japlju delno pogojen s prevodno predlogo. Prav tako je pri opisu oblačila Japelj uporabil prosto opisno zvezo spodej pri nogah ( $2 \mathrm{Mz} 28,33$ in 2 Mz 39,22), ki se pod vplivom Rosalina ${ }^{10}$ orientira glede na telo v oblačilu, medtem ko je uporabil Dalmatin prav tako nazorna opisa (ozdolaj na nje krajih in na nje okrilji), pod vplivom Luthra oba orientirana glede na oblačilo. ${ }^{11}$

(3) Noga je v Bibliji pogosto poosebljena: pomeni (3) osebo ali žival, kateri pripada: Kadar pak ta Golob nej nafhèl, kej bi fe njegova noga pozhilla (1 Mz $8,9) ;{ }^{12}$ Japelj je to mesto prevedel enostavneje, brez noge: Ali kęr letá ny nefhàl, kam bi fędèl..$^{13}$

(4-6) 66-krat v celotni Dalmatinovi Bibliji (od tega kar 39-krat v 2 Mz, ki opisuje zunanjščino in notranjščino svetega šotora ter njegovo gradnjo in opremljanje) se nanaša noga na nežive predmetne denotate, ki jih lahko pomensko opredelimo kot (4) 'spodnji, ožji del predmeta, naprave, ki drži, ohranja telo v pokončnem položaju', in sicer pri mizi ${ }^{14}$ in deski; ${ }^{15}(5)$ 'spodnji, širši del predmeta, naprave, ki drži, ohranja telo v pokončnem položaju', in sicer pri svečniku; ${ }^{16}$ (6) 'telo, predmet, na katerem kaj stoji; podnožje, podstavek', in sicer pri stebru, ${ }^{17}$ oltarju, ${ }^{18}$ oltarnem ognjišču, ${ }^{19}$

8 D: Tiga Ouna pak ima hh na koffe reffékati, inu njegou Drob, inu Golena oprati $\rightarrow$ J: Tiga

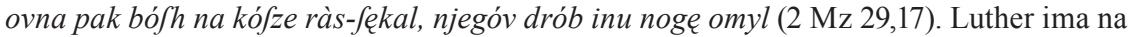
tem mestu sein eingeweide wasschen vnd schenckel, Rosalino den Füssen waschen - Dalmatin in Japelj se torej tudi tokrat $\mathrm{v}$ izboru prekrivata s svojima prevodnima predlogama.

9 D: inu en Madras na ftèsi, inu bo Kojna v' peto vgrisnil $\rightarrow \mathrm{J}$ : ena rogata kazha na ftèsi, katęra konja v' nógo vpizhi (1 Mz 49,17). Luther ima na tem mestu Dan wird ... das Pferd in die ferssen beisen, Rosalino pa welche in die Fußsohlen des Pferdes beisset. Edino v tem primeru je pomenski razkorak tako med Dalmatinom in Luthrom kot tudi med Japljem in Rosalinom.

${ }^{10}$ Rosalino: Herabwärts aber gegen die Füsse (2 Mz 28,33); Unten an den Füssen (2 Mz $39,22)$.

${ }^{11}$ Ustrezno mesto iz $2 \mathrm{Mz} 28,33$ je pri Luthru izpričano takole: unten an seinem Saum, mesto iz 2 Mz 39,22 pa se glasi: er macht den seidenrock zum Leibrock.

${ }^{12}$ Luther ima na tem mestu: Da aber die Taube nicht fand, da jr fuss rugen kund, kar prav tako ustreza Dalmatinovemu prevodu, saj je kund stara oblika pomožnega glagola können v pretekliku in rugen stara oblika glagola ruhen, ki pomeni tudi 'počivati' (Luther III 1974, 346, 362).

${ }^{13}$ Japelj ni sledil Rosalinu, ki piše tako kot zgoraj Luther in Dalmatin: Als aber dieselbe nichts fand, wo ihr Fuß ruhen konnte. Enak tip formulacije, torej različen od Japlja, je tudi v Vulgati: Quae, cum non invenisset ubi requiesceret pes eius.

${ }^{14} \mathrm{D}$ : inu je nje djal na te Shtiri kraje, na nje Shtirih Nogah, raunu pod to Lajfhto, de fo fe Jkusi njo Shtange vtikale, de fe je ta Mysa mogla no/siti (2 Mz 37,13-14).

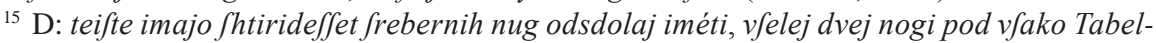
nizo (2 Mz 26,19).

${ }^{16}$ D: Ti imafh tudi en Svejzhnek fturiti is zhiftiga kovaniga slatá, na tém bo enu *Stalu $<*$ noga $>(2 \mathrm{Mz} 25,31)$.

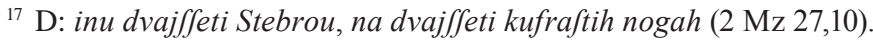

${ }^{18}$ D: LEtu je pak tiga Altarja mera ... Njegova Noga je en komulz viffoka (Ezk 43,13).

${ }^{19}$ D: Ariel pak je bil dvanajft komulzeu dolg, inu dvanajft komulzeu fhirok ... inu njegova Noga je bila en komulz viffoka, inu njegove Shtable fo bilé pruti Iutru (Ezk 43,16-17). 
$\hookrightarrow \quad$ umivalniku $^{20}$ in zagrinjalu ${ }^{21}$. Primerjava z Luthrom, ki ima za navedene pomene fus, füssen, pri svečniku pa schafft, ki ga Dalmatin v besedilu prevaja s stalom, na robu pa ga razlaga z nogo - pokaže popolno prekrivnost z Dalmatinom. V Japljevem prevodu je pri mizi in deski zapisana noga, medtem ko je pri umivalniku in stebru podstava, pri svečniku (enako kot pri Dalmatinu) ter pri oltarju in oltarnem ognjišču pa stalo, kar kaže na večjo specializacijo izrazov. Dalmatinov primer iz $2 \mathrm{Mz} 38,31$ : Inu noge tiga Dvora okuli inu okuli, inu noge téh Vrat na Dvoru je danes pomensko težko razumljiv, pri Japlju pa se glasi: Inu podftave tiga dvorifha takú dobru okuli, kakòr na njega vratih. Primerjava s prevodnimi predlogami je pokazala njihov vpliv na slovenski besedili. ${ }^{22}$

$\mathrm{V}$ dveh primerih je Japljeva noga neustrezno rabljena namesto Dalmatinove besede rog. ${ }^{23}$ Ker se Luther, Vulgata in Rosalino $\mathrm{z}$ rabo besed hörner in cornua ujemajo z Dalmatinom, gre pri Japlju očitno za napako.

Frazemov je v ožji, konkordančni skupini malo. Prvi je iz 2 Mz 21,23-25: dati nogo za nogo 'enako vrniti z enakim' in se v Dalmatinovem prevodu glasi: taku ima dana biti Dufha sa Dufho, Oku sa Oku, Sob sa Sob, Roka sa Roko, Noga sa Nogo, Opezhenje sa Opezhenje, Rana sa Rano, Zhernauka sa Zhernauko. V jeziku sta živa samo dva elementa: oko za oko in zob za zob, rabljena skupaj ali posamezno. ${ }^{24}$

Drugi frazem je iz $1 \mathrm{Mz}$ 41,44: pres tvoje vole néma nihzhe fvojo roko ali nogo ganiti po vfej Egyptoufki desheli in pomeni 'ne sme ničesar storiti oz. nikamor iti'.

Kalkirana zveza možje $k$ nogam ${ }^{25}$ (Luther: sechs hundert tausent Man zu fuss) je $\mathrm{v}$ besedilu označena $\mathrm{z} *$ in na robu pojasnjena s sopomenko pešci ( $\mathrm{v}$ celotni Bibliji se pojavlja ta zveza še na dveh mestih), kar kaže tako na Luthrov vpliv kot na Dalmatinovo zavest o neustreznosti zveze; samostalnik pešci je na tem mestu uporabil tudi Japelj (V: sescenta fere milia peditum virorum), enako tudi SP 1997. Samo enkrat v celotni Dalmatinovi Bibliji ni omenjena Luthrova zveza prevedena kalkirano: Jhtiri krat ftutaushent Mosh pejfhzou (Sod 20,2). V SSKJ je

${ }^{20} \mathrm{D}$ : Vmivalnik is kuffra, inu njegovo Nogo is kuffra (2 Mz 38,8).

${ }^{21}$ D: Is téh ftu centou Srebra fo ony slyli Noge te Svetinje, inu Noge tiga Pèrta, ftu Nug is ftu Centou (2 Mz 38,27).

${ }^{22}$ Luther: Dazu die füsse des Vorhofs rings rumb / vnd die füsse des thors am Vorhofe; Vulgata: et bases atrii, tam in circuitum quam in ingressus eius; Rosalino: Dazu die Fußgestelle des Vorhofes, sowohl in seinem Umfange, als Eingange.

${ }^{23} \mathrm{D}:$ njegove krij imafh vseti, inu jo $s^{\prime}$ tvoim pèrftom na tiga Altarja Rogé djati $\rightarrow \mathrm{J}:$ kar vsamefh od kryví tiga telęta pomashi noge tiga Altarja s' tvojim pèrftam $(2 \mathrm{Mz} 29,12)$. Dalmatin ima k 2 Mz 27,2 dodano opombo z razlago, kaj je rog: tu fo bily majhini Stebèrci na Shtirih vogleh tiga Altarja, s' Knoffy inu s' isresanimi roshizami. Sveto pismo 1997 ima na obeh mestih rogovi.

${ }^{24}$ Po analogiji z navedenimi frazemskimi zvezami obstaja $\mathrm{v}$ živem jeziku tudi frazem glava za glavo. V SSKJ je razložen kot 'če je kdo zakrivil človekovo smrt, naj se kaznuje s smrtjo', kar je v primerjavi z zgoraj navedeno določnejša razlaga. V Svetem pismu ni ta zveza nikjer izpričana (Beseda 98).

${ }^{25}$ Navedek je iz Dalmatinove 2 Mz 12,37: okuli fheftkrat ftutaushent Mosh $\boldsymbol{k}^{\prime}$ nogam <*ali pejfhzou>. 
zabeležena prislovna zveza iti k nogam, označena kot nižje pogovorna, medtem ko pridevniškega pomena zveze, izpričanega v Dalmatinu, v SSKJ ni. ${ }^{26}$

Vzdigniti svoje noge 'podati se na pot' je slikovita Dalmatinova zveza iz 1 Mz 29,1: Iacob je pak fvoje noge vsdignil, ${ }^{27} \mathrm{ki}$ jo je Japelj nadomestil z izrazno enostavnejšo: Jakob fe je tèdaj dalej podál. ${ }^{28} \mathrm{~V}$ navedenih zgledih se je pomen noge razvil iz njene funkcije, vezane na premikanje, hojo, ki se lahko frazemsko poveže tudi z rezultatom premikanja (1 Mz 30,30): GOSPVD je tebe shegnal fkusi mojo ${ }^{k}$ nogo, ki je razložena v opombi: ${ }^{k}$ tu je, ker fim jeft moral fem tèr tam tekati, de fi ti taku bogat poftal. Moja noga je tu morala opraviti, ${ }^{29}$ je pri Japlju npr. zamenjana s pomensko jasnejšo: po mojim prihódi je Gofpód tebe poshęgnal, ${ }^{30}$ ki ne potrebuje dodatne razlage. Prav tako ne uresničitev v SP 1997: Gospod te je blagoslovil za vsak moj korak.

1.2 Upoštevanje celotne Dalmatinove Biblije (435 pojavitev) ${ }^{31}$ vnaša malo sprememb v osnovno pomensko zgradbo besede noga. Predstavljenim pomenom se pridružuje le še noga (7) kot okončina kipa: Tigaiftiga Pilda glava je bila is zhiftiga Slata ... njegove Noge fo bilé en dejl shelesne en dejl yllovate (Dan 2,33).

Pač pa celotna Dalmatinova Biblija precej razširi frazeologijo besede noga. ${ }^{32}$ Zlasti prevladujejo glagolski frazemi s sestavino noga: pasti pod noge koga 'podrediti se komu' in dati koga pod noge komu/podvreči kaj nogam koga 'podrediti koga/kaj komu': Ony bodo morali pod moje noge pafti (L: Sie müssen vnter meine füsse fallen - Ps 18,39), ${ }^{33}$ GOSPVD je nje pod vafhe noge dal (L: der HERR hat sie vnter ewre füsse gegeben - Jdt 14,5), ${ }^{34}$ Ti fi vfe rizhy njegovim nogam podvèrgal ${ }^{35}$ (L: Alles hastu vnter seine Füsse gethan - Ps 8,7). ${ }^{36}$

Biti lahkih nog 'hitro, z lahkoto hoditi, teči': Asael pak je bil lahkih nug, kakòr

${ }^{26}$ Prav tako ni tega pomena v Kastelec-Vorenčevem slovarju pa tudi 200 let kasneje v Pleteršnikovem ne.

${ }^{27}$ Luther ima na tem mestu: DA hub Jacob füsse auff, kar pomeni njegov neposredni vpliv na Dalmatina.

${ }^{28}$ Rosalinov prevod tega mesta ni dobesedno prekriven z Japljevim: Also zog Jacob hin.

${ }^{29}$ Luther ima na tem mestu formulacijo, ki jo je očitno - skupno z opombo - posnel Dalmatin: der HERR hat dich gesegenet durch ${ }^{f}$ meinen fus.

${ }^{30}$ Prevedek se ujema z Rosalinom po smislu, ne pa dobesedno: der Herr hat dich, nachdem ich zu dir eingegangen bin, gesegnet.

${ }^{31}$ V Sekciji za zgodovino slovenskega jezika pri Inštitutu za slovenski jezik Frana Ramovša so popolni izpisi vseh slovenskih besedil slovenskih protestantskih piscev iz 16. stoletja. Za ta prispevek sem uporabila izpise noge in glave iz Dalmatinove Biblije.

${ }^{32}$ Kržišnik - Kolšek $(1990,144)$ navaja posredno ugotovitve Romunke Slave, da so poimenovanja delov telesa med najpogostejšimi sestavinami frazemov: glava, kri in roka so na prvih treh mestih.

33 J: ony fo meni pod nóge pádli; SP 1997: padejo pod moje noge.

${ }^{34} \mathrm{~J}$ : sakaj Gofpód bo nję ftàrel pod vafhimi nogami; V: quoniam Dominus conteret eos sub pedibus vestris.

35 Variante v Dalmatinu so (pod)vreči njegovim nogam/pod njegove noge.

${ }^{36} \mathrm{~J}$ : Vee fi ti njegóvim nogám podvèrgèl. 
$4 \quad$ ena Sèrna na púli (L: Asahel aber war von leichten füssen wie ein Rehe auff dem felde - 2 Sam 2,18). ${ }^{37}$

Primerjava z Luthrom kaže v vseh primerih medsebojno prekrivnost, z Japljem pa $\mathrm{v}$ prvem in tretjem; $\mathrm{v}$ drugih dveh primerih ima Japelj prosti zvezi: streti jih pod vašimi nogami; biti silno hiter $v$ teku. Frazem dati pod noge je analogen $\mathrm{z}$ dati $v$ roke, saj oba pomenita možnost razpolaganja z nekom, je pa dati $v$ roke bolj živ (Kržišnik - Kolšek 1990, 147-148; gl. noga in roka v SSKJ). Pomen podreditve v zgornjih dveh frazemih je predvidljiv, saj je noga $\mathrm{v}$ Bibliji simbol in nosilka oblasti (Grabner-Haider - Krašovec 1984, 486).

Zveza (po)teptati/treti koga z nogami ne pomeni fizičnega teptanja, pač pa sovraštvo do nekoga oz. željo po njegovem uničenju: ${ }^{38}$ Kateri je moj Kruh jedil, taifti mene s'nogami teptá (Ps 41,10) in Kateri moj kruh jej, ta mene s'nogami tare $(\mathrm{Jn} 13,18) .{ }^{39} \mathrm{~V}$ obeh primerih ima Luther glagol treten.

Pogost frazem v Dalmatinu je od mladih nog 'od mladosti', ki ni motiviran z Luthrom (von Jugent, von kind), prav tako se ne pojavlja v Japlju (od (moje) mladofti) in SP 1997 (od otroštva, od mladih let), čeprav je živ še danes.

Prav tako se je, sicer variiran, ohranil v Dalmatinu rabljeni frazem od glave do nog 'v celoti', ${ }^{40}$ ki pa je izrazno in pomensko prekriven z Luthrom (von dem heubt an bis auff die füsse); enako velja za njegovo izrazno-pomensko še natančnejšo varianto od podplatou téh nug do vèrha glave (Luther: von der fussolen an bis auff seine scheitel).

Zveza pokrivati svoje noge se v Dalmatinu (1 Sam 24,4) pojavlja kot evfemizem za 'opravljati potrebo'; izpričana je v Luthru, na njen omiljevalni način izražanja pa je opozorjeno v opombi tako v Luthru kot Dalmatinu, medtem ko je v opombi v SP 1997 naveden dobesedni prevod iz originala: si pokril noge, v rednem besedilu pa je opravil potrebo.

V posebno skupino spadajo zveze, ki pomenijo simbolna dejanja in so zaradi svojega opisovanja realnega $\mathrm{v}$ Bibliji (morda) šele na poti v frazem, npr. otresti prah od nog: Inu kateri kuli vas nebodo gori vseli, ni poflufhali, ondi pojdite prozh vunkaj, inu otrefite prah od vafhih nug, k'eni prizhi zhes nje - Mr 6,11. V SP 1997 (str. 1492 v opombi) je otresti prah od nog razloženo kot kretnja, ki izraža željo po prekinitvi določene medčloveške vezi in je bila pri Judih znak prezira, ko so se vračali iz poganskih krajev.

Enak pomen ima tudi zveza otresti prah s svojih oblačil (SP 1997, 1668). Pri Dalmatinu se to mesto (Apd 18,6) glasi: je on gvant iftrefsil. Po Bibličnem leksikonu $(1984,521)$ je to znamenje radikalne prekinitve vsakršne skupnosti z nekim krajem in njegovimi prebivalci. V SSKJ zveza ni navedena ne med frazemi ne med prostimi zvezami, v elektronski zbirki Nova beseda pa jo najdemo samo kot citat iz Biblije.

Podobno simbolno dejanje, ki pa ni vezano samo na biblijska besedila, je (doli)

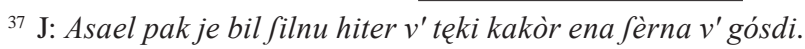

${ }^{38}$ Gl. Sveto pismo 1997, 1627.

${ }^{39}$ Po Bibličnem leksikonu (Grabner-Haider - Krašovec 1984, 486) je to znak zaničevanja.

${ }^{40} \mathrm{D}$ : inu pokryo vfo Kosho, od glave do nug - $3 \mathrm{Mz} 13$,12; SP 1997: od glave do peta; SSKJ: od nog do glave. 
pasti (nekomu/pred nekoga/na svoje obličje) $k$ nogam, npr. v Raz 19,10: Inu jeft fim padèl pred njega k'njegovim nogam, de bi ga molil. To dejanje je znamenje ponižnosti in podrejenosti, vendar je lahko tudi nehoteno in nima simbolnega pomena, npr. v Sod 5,27: On fe je krivil, je doli padil k'nje nogam, kakòr fe je svial, taku je leshal konzhan.

V skupino simbolnih dejanj oz. položajev spada sesti k nogam koga, npr. v 5 Mz 33,3: Ony bodo h'tvoim nogam fejdli, inu fe bodo vuzhili od tvoih befséd. V drugem poglavju 2. knjige kraljev sta v opombi razloženi kot opozicijski biti pri glavi in biti pri nogah: Pèr glavi biti, fe rezhe druge vuzhiti: Pèr nogah biti, fe rezhe od drugih fe vuzhiti, kakòr ta Shular. Sakaj kadar Shulmefhter vuzhy, taku on vifhe fedy kakòr njega Shularji.

2.1 Glava se v treh konkordančno izpisanih besedilih pojavlja pri Dalmatinu 41-krat, pri Japlju pa 30-krat, od tega je 26 pojavitvenih mest prevodoma skupnih. Kljub razmeroma nizkemu številu pojavitev je pri Dalmatinu izpričanih kar pet osnovnih pomenskih enot:

(1) '(zgornji) del človeškega telesa z možgani': je vsel ta Kamen, kateri je bil pod fvojo glavo polushil (1 Mz 28,18);

(2) '(sprednji) del živalskega telesa z možgani': njegovi Synuvi imajo fvoje roke poloshiti timu Iunzu na Glavo (2 Mz 29,10);

(3) 'človek':41 inu vsami sa flejdno glavo en Gomer, po zhifli téh Dufh v' fvoji Vtti (2 Mz 16,16);

(4) 'vodilni človek v skupini': je nje poftavil h' glavam zhes ta folk (2 Mz 18,25); Letu fo te Glave mej Ozheti Levitovih shlaht (2 Mz 6,25); ${ }^{42}$

(5) 'okroglast vrhnji del stebra': fo bily fturjeni téh Stebrou Knoffi, inu nyh Glave okovane, inu nyh Obrozhi (2 Mz 38,28).

Tudi Japljeva glava je večpomenka, vendar zadnjih dveh Dalmatinovih pomenov Japljeva tri besedila ne izkazujejo več. V pomenu 'vodilni človek v skupini' je zamenjana glava z besedama oblastnik in poglavar, ${ }^{43} \mathrm{ki} v$ Dalmatinovi Bibliji sploh še nista zabeleženi, ${ }^{44}$ vrhnji del stebra pa je pri Japlju glavica. ${ }^{45}$ Dalmatinov opis vrh glave je zamenjal Japelj s preciznim leksemom teme, ponekod pa je glavo enostavno izpustil (jesti iz te korbe na moji glavi $\rightarrow$ jesti iz nje; tega vikšiga teh ključarjov/

${ }^{41}$ Po SSKJ je glava v pomenu 'človek' zlasti glede na njegove značilnosti, umske sposobnosti. V obravnavanih svetopisemskih besedilih ni pri tem pomenu izpostavljena nobena človekova sposobnost niti značilnost.

${ }^{42}$ Luther ima na obeh mestih Heubter.

${ }^{43} \mathrm{~V} 2 \mathrm{Mz}$ 18,25 pravi Japelj: inu ene je sa oblaftnike zhes ludftvu ... poftavil. $2 \mathrm{Mz} 6,25$ pa se pri Japlju glasi: Lety fo poglavarji Levitovfkih shlaht.

${ }^{44}$ Dalmatin ima samo oblast in poglavnik.

${ }^{45} \mathrm{~V}$ Japljevem prevodu se to mesto glasi: je on fturil glavize tih ftèbrov, letę ftèbré je on tudi $s^{\prime}$ frębram povlęjkel $(2 \mathrm{Mz} 38,28)$. Prevedek je za Japlja značilen, medtem ko je glava v tem pomenu pri Dalmatinu netipična. V pomenu 'okroglast vrhnji del stebra' ima Dalmatin najpogosteje besedo glavič (Narat 1999, 112-113). 
$\rightarrow \quad$ fištrov glava $\rightarrow$ ta vikši teh ključarjov/pekov) in s tem jezik poenostavi. ${ }^{46}$ Oboje ni rezultat Japljevega zavestnega krčenja oz. izboljševanja jezika, pač pa je pogojeno s predlogo. ${ }^{47}$ Podobno gre pri Dalmatinu za prevodno odvisnost od Luthra. ${ }^{48}$

Frazemov s sestavino glava je v izpostavljenih treh besedilih malo: kaj priti čez glavo koga 'kdo postati deležen česa': D: shegni tvojga Ozheta ... imajo priti zhes Iosephovo glavo ${ }^{49} \rightarrow \mathrm{J}:$ Shęgni tvojga ozhęta ... naj fe dopólnio nad Jósephovo glavó $^{50} \rightarrow$ SP: Blagoslovi tvojega očeta ... Naj pridejo na Jožefovo glavo $(1 \mathrm{Mz}$ 49,26).

Dalmatinovo zvezo v $1 \mathrm{Mz}$ 27,12: bom fam zhes fe pèrpravil prekletje, inu nikar Shegen je Japelj zamenjal s frazemom: de fi jeft na męti shęgna klętu na glavo ne nakóplem.

Že navedeni Dalmatinov frazem povišati glavo koga 'dati komu višji položaj' in 'obesiti koga' je besedna igra z dvojnim smislom (gl. $1 \mathrm{Mz} 40,12-13,18-20):{ }^{.1}$ Try mladice, fo try dnévi. Zhes try dny bo Pharao tvojo glavo povifhal, inu te bo fpet v' tvoj pèrvi ftan poftavil ... Try Korbe fo try dnevi, inu zhes try dny bo Pharao tvojo glavo povifhal, inu tebe na Galgo obéfsil ... inu je povifhal tiga vifhiga téh Kluzharjou glavo, inu tiga vifhiga téh Fifhtrou glavo. Japelj je besedno igro nadomestil z nedvoumno in jasno formulacijo: Try mladike pomęnio fhe try dny. Po katęrih bó Pharao na tvojo Jtręshbo Jpómnil, inu bó tebe v' tvojo pèrvo flushbo nasaj poftavil ... Try pletenize pomęnio Jhe try dny. Po katęrih bó Pharao tebi glavó vsęl, inu te bó potle na en krish obęsil ... fi je med jèdjó Jpómnil na tiga Vikfhiga

${ }^{46} \mathrm{Za}$ ta prikaz so potrebna daljša ponazorila. Prvi primer $(1 \mathrm{Mz} 40,17)$ se pri Dalmatinu glasi: inu v' tej sgurajni Korbi voo shlaht pezheno Shpendio Pharaonu, inu Ptice fo jédle is te Korbe na moji glavi; medtem ko ima Japelj na tem mestu: Inu de fim v' eni pletenizi, katęra je na vèrhi bilá, vfe fórte jedy od teftenine nefsèl, inu de fo ptize is nję jędle.

Drugi primer (1 Mz 40,20-22) se pri Dalmatinu glasi: je povifhal tiga vikfhiga téh Kluzharjou glavo, inu tiga vikfhiga téh Fifhtrou glavo, mej fvojemi Hlapci, inu je tiga vifhiga téh Kluzharjeu Jpet poftavil v' njegovu Kluzharftvu, de je Pharaonu Pehar v' roke dajal: Ali tiga vifhiga téh Fifhtrou je on puftil obéfiti. Japelj ima na tem mestu: katęri je fvojim flushabnikam enu veliku goftovanje narędil, inu fi je med jèdjo Jpómnil na tiga Vikfhiga tih kluzharjov, inu na tiga Vikfhiga tih pękov. Inu eniga je v' njegóvo flushbo nasaj poftavil, de bi njemu tó pytno po/sódo podajal. Tiga drugiga pak je na galge puftil obęsit.

${ }^{47} \mathrm{~V}$ Rosalinovem prevodu je prvi primer $(1 \mathrm{Mz} 40,17) \mathrm{v}$ naslednji, z Japljevim prevodom prekrivajoči se obliki: Und trüge in dem obersten Korbe allerhand nach der Beckerkunst gebackene Speisen, daraus die Vögel frassen; drugi primer (1 Mz 40,20-22) se prav tako prekriva z Japljem: und er richtete seinen Dienern eine grosse Mahlzeit an; bey dem Essen aber gedachte er des Oberschenkens, und Oberbeckers. Und er setzte den einen wieder in sein Amt, damit er ihm ... Becherreichte. Den andern ließ er an den Galgen aufhängen.

${ }^{48} \mathrm{~V}$ Luthrovem prevodu sta oba primera prekrivna z Dalmatinom, tako $1 \mathrm{Mz}$ 40,17: vnd im öbersten korbe allerley gebacken Speise dem Pharao / Vnd die Vogel assen aus dem korbe auff meinem Heubt; kot tudi $1 \mathrm{Mz}$ 40,20: das Heubt des öbersten Schenken / vnd das Heubt des öbersten Beckers.

${ }^{49}$ Luther ima na tem mestu: vnd sollen kommen auff das heubt Joseph.

${ }^{50}$ Vulgata: fiant in capite Ioseph.

${ }^{51}$ Tako so poimenovane te formulacije v Svetem pismu 1997 (str. 93, opomba). 
tih kluzharjov, inu na tiga Vikfhiga tih pękov. Sodobni standardni prevod ohranja Dalmatinov izrazni način, ker ustreza originalu, in v opombah opozarja na popolno različnost pomenov iste zveze. ${ }^{52}$

2.2 V celotni Dalmatinovi Bibliji se glava pojavlja 532-krat, vendar ta množica pojavitev - enako kot pri besedi noga - dopolnjuje osnovno pomensko strukturo le s pomenskim odtenkom k 1) oz. 2): 'zgornji/sprednji del kipa človeškega/živalskega telesa', medtem ko je zveza prisegati pri svoji glavi že frazem 'podkrepiti trdnost svoje prisege z zastavitvijo lastnega življenja': Ti némafh tudi pèr tvoji Glavi prifsegati (Mt 5,36).

Večkrat izpričan je npr. frazem vaša kri bodi čez vašo glavo ${ }^{53} \mathrm{z}$ variantami tega kri bodi na njega glavi, kri Abnerja padi nad Joabovo glavo in njiju kri bo plačana na Joabovo glavo, s pomenom 'nositi odgovornost za smrt koga, za svoje ravnanje'. Prvi primer (Apd 18,6) nam s sobesedilom razkrije, da gre za pravi frazem: Kadar fo ony pak supèr govurili inu Shentovali, je on gvant iftrefsil, inu je djal k'nym:

\section{Vafha kry bodi zhes vafho glavo.}

Variante Dalmatinovega frazema položiti/vreči/dati dejanje/zasluženje koga na glavo ${ }^{54}$ pomenijo 'terjati od koga račun za njegova dejanja'. Razlaga je vzeta iz opombe v SP 1997 k Ezk 9,10; sodobni prevod se ujema z Dalmatinom: Njihovo ravnanje bom spravil na njihovo glavo. Japelj je frazem nadomestil z variirano prosto zvezo povrniti njim po njih delih/zasluženju, ${ }^{55} \mathrm{ki}$ ni utemeljena v Vulgati in je očitno rezultat prevajalčevega (Škrinjar s svojo skupino) tvornega odnosa do predloge.

Dalmatinov frazem ne imeti, kamor bi svojo glavo položil (Mt 8,20): Ptice pod Nebom imajo gnesda: Ampak Syn tiga zhloveka néma, kam bi jvojo glavo polushil v pomenu 'ne imeti stanovanja, prenočišča'. Glagol položiti uporablja v tej zvezi še Japljev svetopisemski prevod, medtem ko ima Wolfov prevod iz leta 1856 in vsi nadaljnji glagol nasloniti.

Po svoji glavi ravnati 'ne ozirati se na mnenje drugih' je iz Dalmatinovega predgovora k Prvemu pismu Korinčanom: kakòr de bi velika framota bila, kadar bi fleidni kaj fußebniga naprej nevsel, inu po fvoji laftni glavi nerounal. V SSKJ zveza ni uvrščena med frazeme, ampak neustrezno med zglede, ki dokazujejo pomen glave kot 'ta del pri človeku kot središče njegovega razumskega in zavestnega življenja'.

Pasti kaj (komu) na njegovo glavo 'doleteti koga kaj slabega, zgoditi se komu kaj slabega', npr. Ps 140,10: Padi ta nefrezha na nyh glavo. ${ }^{56} \mathrm{~V}$ Japljevem prevodu je Traven izpustil besedo glava: Vfe njih salásùvanje ... bó na nję pádlu. ${ }^{57}$

${ }^{52}$ V Svetem pismu 1997 se iztržek iz 1 Mz 40,12-13, 18-20 glasi: tri mladike so trije dnevi. Še tri dni in faraon bo povzdignil tvojo glavo in te postavil nazaj v tvojo službo /.../ tri košare so trije dnevi. Še tri dni in faraon bo povzdignil tvojo glavo s tebe in te obesil na drevo /... / Tedaj je sredi svojih služabnikov povzdignil glavo vélikega točaja in glavo vélikega peka.

${ }^{53}$ Luther: Ewer Blut sey vber ewer heubt. SP 1997: Vaša kri nad vašo glavo.

${ }^{54}$ Luther: Sondern ich wil jr Thun auff jren Kopff werffen (Ezk 9,10).

${ }_{55}$ Vulgata: viam eorum super caput eorum reddam.

${ }^{56}$ Luther: Das vnglück ... Müsse auff jren Kopf fallen.

${ }^{57}$ Vulgata: Caput circuitus eorum, labor labiorum ipsorum operiet eos. 
Živo oglje spravljati na glavo koga se v Dalmatinu (Rim 12,20) glasi: Aku je tedaj tvoj Sovrashnik lazhen, taku ga nafiti ... Sakaj kadar ti letu fturifh, taku ti shivu ogele fpravla/h na njegovo glavo. V robni opombi je zveza razložena: fe fovrashnik fkusi tvojo dobruto fam zhes fe referdi, de je on tebi taku hudu fturil. Japljev $^{58}$ in standardni prevod ${ }^{59}$ se z Dalmatinom ujemata; v standardnem prevodu sta navedeni v opombi dve možni razlagi tega mesta: 1) poostrena Božja kazen, ki bo doletela nasilneža, če se bo v dobroti žrtve še jasneje zrcalila njegova hudobija; 2) bolečina kesanja, kazen pekoče vesti. V Novi besedi je zgled iz F. Milčinskega: Primanjkljaj petinšestdeset kron in šestintrideset vinarjev je bil pokril iz lastnega žepa, da zbere žarečega oglja na glave svojih nasprotnikov, zakaj bil je uverjen, da se mu godi krivica. Gre za nekoliko spremenjen biblijski citat s pomenom 'vzbuditi komu slabo vest'.

Glava se pojavlja tudi v številnih zvezah, ki upovedujejo simbolna dejanja. Zelo znan in na Biblijo vezan primer je trositi/potresati/raztresati/posipati/metati na svojo glavo prah/pepel/prst/pepel in prah. To dejanje je v Bibliji in v kulturah Bližnjega vzhoda sploh pomenilo znamenje žalovanja, tudi pokore (prim. še valjanje po pepelu, sedanje v pepel, trganje svojih oblačil). Zveza posuti se s pepelom je danes živa predvsem v publicistiki: ${ }^{60}$ Tisti, ki je kriv, naj se hitro posuje s pepelom in $v$ prihodnje za obči blagor drži jezik za zobmi, in ima s pomenom '(javno) obžalovati kaj, pokesati se' vse značilnosti frazema. ${ }^{61}$ Glava ni ostala del tega frazema. V Novi besedi najdemo Cankarjevo prenovo tega frazema: Nato ne gre $k$ spovedniku, ne $k$ sodniku, ne posuje si temena s pepelom, ne obleče meniške halje, ki ga lahko razumemo kot niz spokornih dejanj.

Stresati/potresati (z) glavo (čez nekoga/za nekom) pomeni izražati s temi gibi nestrpnost oz. odpor do nekoga, pri tem pa gre zgolj za ubesedeno govorico telesa, ne za pomenski premik.

Žalbati glavo z oljem / izliti žalbovo olje na glavo - s tem dejanjem se podeljuje komu duhovniška ali kraljevska čast, v Novi zavezi pa je to dejanje znamenje spoštovanja in ljubezni (Biblische Realkonkordanz, 643), npr. Lk 7,46: Ti néfi moje Glave s'ojlem shalbal: Ona je pak moje noge s'shalbo shalbala.

\section{Zaključek}

Besedi noga in glava imata $\mathrm{v}$ Japljevem prevodu v treh konkordančno izpisanih besedilih manj pomenov kot v Dalmatinovem. Nogo (4) 'spodnji, ožji del predmeta, naprave, ki drži, ohranja telo v pokončnem položaju' ohranja Japelj samo pri mizi in deski, medtem ko je pri vseh drugih predmetih zamenjana s podstavo ali stalom. Za

\footnotetext{
$58 \mathrm{~J}$ : taku bófh sherjavzo nad njegóvo glavó vkùp fpravlal.

${ }^{59}$ SP 1997: boš sipal žarečega oglja na njegovo glavo.

${ }^{60} \mathrm{~V}$ zbirki Nova beseda zlasti v besedilih iz Državnega zbora in iz časnika Delo.

${ }^{61}$ Simbolno dejanje, ki je prešlo v frazem, je npr. tudi umiti si roke, le da v zgledu iz Kreljeve Postile slovenske (str. CLXIb), ki ga navaja Novak 2004 (str. 186), ta prehod še ni izveden, ker gre za sočasnost fizičnega in govornega dejanja: Pilatuf ... vsame vode, inu roke vmije vprizho vfiga Folka rekoch: Ias néfàm dolshan na tei krij letiga pravizhniga.
} 
dva Dalmatinova pomena glave ('vodilni človek v skupini' in 'okroglast vrhnji del stebra') ima Japelj izraze oblastnik in poglavar ter glavica.

Celotna Dalmatinova Biblija prinaša poleg šestih pomenov noge in petih pomenov glave iz konkordančnih izpisov še po enega pri vsaki besedi, kar je glede na veliko večji besedilni obseg zelo malo. Je pa v celotni Dalmatinovi Bibliji izpričanih veliko več frazemov - v konkordančnih izpisih je frazeologija pri obeh avtorjih skromna, kar je zaradi omejenega obsega razumljivo, najzanimivejša pa je zveza povišati glavo nekoga, ki je rabljena kot besedna igra z dvojnim smislom - ter več opisov simbolnih dejanj, ki kasneje postanejo frazemi (posuti se s pepelom) ali pa tudi ne (otresti prah od nog). V frazeologiji se primerjana prevoda večkrat razlikujeta, medtem ko so si opisi simbolnih dejanj v vseh bibličnih prevodih - kar je razumljivo - zelo podobni, če že ne enaki.

\section{Viri in literatura}

Beseda 98, Slovenski standardni prevod Svetega pisma na CD-ROM-u, 1998, Ljubljana, Svetopisemska družba Slovenije.

Bibel-Lexikon, 1968, Zürich-Köln, Benzinger Verlag Einsiedeln.

Biblische Realkonkordanz, 1913, Regensburg.

Breznik, Anton, 1928, Japljev prevod sv. pisma, Časopis za slovenskijezik, književnost in zgodovino $7,77-107$.

Dalmatin, Jurij, 1584, BIBLIA, TV IE, VSE SVETV PISMV, Wittemberg, Faksimile, Ljubljana 1968.

Grabner-Haider, Anton, in Krašovec, Jože, s sodelavci, 1984, Biblični leksikon. Celje, Mohorjeva družba.

Japelj, Jurij, in sodelavci, 1784-1802, SVETU PISMU STARIGA INU NOVIGA TESTAMENTA, I-X, Ljubljana.

Kastelec - Vorenc, gl. Stabej.

Kržišnik - Kolšek, Erika, 1990, Sestavina roka v frazeologemih slovenskega knjižnega jezika, Seminar slovenskega jezika, literature in kulture 26, 141-154.

Kržišnik, Erika, 2000, Biblične stalne zveze v Slovarju slovenskega knjižnega jezika in v slovenskem jeziku, Razprave / Dissertationes XVII, 67-80.

Luther, D. Martin, 1545, Biblia, Das ist die gantze Heilige Schrifft Deudsch auffs new zugericht, I-III, Wittenberg. München, Deutscher Taschenbuch Verlag, 1974.

Narat, Jožica, 1999, Semantika samostalnika v jeziku Jurija Dalmatina in Jurija Japlja, Doktorska disertacija, Ljubljana, Filozofska fakulteta, 214 str. [Tipkopis.]

Nova beseda - Besedilni korpus na Inštitutu za slovenski jezik Frana Ramovša.

Novak, France, 2004, Samostalniška večpomenskost v jeziku slovenskih protestantskih piscev, Ljubljana, Založba ZRC.

Pleteršnik, Maks, 1894-95, Slovensko-nemški slovar, Ljubljana, Knezoškofijstvo.

Rosalino, Franz, 1793-94, Biblia sacra, oder die heilige Schrift des alten und neuen Testaments, Wien.

Slovar slovenskega knjižnega jezika, I-V, 1970-1991, Ljubljana. 
$-\quad$ Stabej, Jože, 1997, Slovensko-latinski slovar. Po: Matija Kastelec - Gregor Vorenc, Dictionarium latino-carniolicum (1680-1710), Ljubljana, Založba ZRC.

Sveto pismo Stare in Nove zaveze, 1997, Ljubljana, Svetopisemska družba Slovenije.

Vulgata: Bibliorum Sacrorum iuxta Vulgatam Clementinam, Vatikan, 1946. [Nova izdaja.]

\title{
The Life of Words in the Bible: noga (foot) and glava (head)
}

\author{
Summary
}

The author discusses the words noga (foot) and glava (head) in terms of lexicology. These are two nominal constants that appear in both Jurij Dalmatin's and Jurij Japelj's translation of the Bible. Nominal constancy and variability were first established in the selected text corpus - Genesis, Exodus, and the Song of Solomon - based on fully transcribed nouns within a two-line context. For greater clarity, the article extends the analysis of the words noga and glava to all of Dalmatin's Bible, whereas Japelj's translation and the 1997 standard translation of the Bible were only included where necessary.

Nearly the entire basic semantic structure of the words noga (77 occurrences in Dalmatin and 67 in Japelj) and glava (41 occurrences in Dalmatin and 30 in Japelj) is established on the basis of the three selected texts alone. Dalmatin's noga has six different attested meanings, while glava has five; Japelj uses three different meanings for both of them, but replaces the others with other terms. The entire text of the Bible offers only one additional meaning for both words; in general, new features occur in phraseology and citations expressing symbolic acts that may or may not have become phrasemes.

Translations of the Bible from different periods are extremely well-suited for determining linguistic - or in this case, lexical - development because the sacredness of Biblical text does not permit any major conceptual or stylistic alterations. However, major or minor differences occur even between individual translation models (i.e., between Martin Luther's German translation and the Latin Vulgate, or Franz Rosalino's German translation), which result in differences between the Slovenian translations as well.

Jožica Narat

Inštitut za slovenski jezik Frana Ramovša ZRC SAZU

Novi trg 2, 1000 Ljubljana

jozica.narat@guest.arnes.si 